\title{
Reflexiones metodológicas sobre la propiedad privilegiada en la Baja Edad Media: el mayorazgo castellano*
}

\author{
Methodological Thoughts on the Property of the Privileged in the \\ Later Middle-Ages: The Castilian Mayorazgo Entail System
}

\author{
CORINA LUCHÍA**
}

\begin{abstract}
RESUMEN
En este trabajo se propone una reflexión metodológica sobre la conformación de la propiedad privilegiada en la Castilla bajomedieval. El mayorazgo como la forma más protegida de disposición patrimonial es pensado como parte de los procesos de negociación, que informan la conducta de los grupos privilegiados, tendiente a la configuración de sus posiciones de supremacía. La amplia casuística que caracteriza esta institución es resultado de la plasticidad con que los sectores de poder elaboran sus estrategias de reproducción. Las variables condiciones que hacen a la existencia de los patrimonios vinculados se expresan en las numerosas excepciones contempladas en la propia regla.
\end{abstract}

\section{PALABRAS CLAVE}

Mayorazgo, Castilla, estrategias, poder, patrimonio, reglas, excepciones.

\section{ABSTRACT}

This study proposes to reconsider the methodology regarding the creation of the property of the privileged classes in Late-Medieval Castile. The "mayorazgo» entail system became the property transmission mechanism with most guarantees which resulted from the negotiation processes based on the behaviour of privileged groups in their quest for power. The wide array of idealtypes that characterizes this institution is the product of the flexibility of the system utilized by these privileged groups as strategies of reproduction. The various conditions existing in the entail system is also the result of numerous exceptions contemplated in the rule.

\section{KEY WORDS}

Mayorazgo Entail System, Castile, Strategies, Power, Property, Rules, Exceptions.

\footnotetext{
* Fecha de recepción del artículo: 2013-10-7. Fecha de aceptación del artículo: 2013-11-7.
}

** Universidad de Buenos Aires-CONICET. C.e.: corinaluchia@filo.uba.ar 


\section{PRESENTACIÓN}

El régimen de mayorazgo castellano ha sido objeto de numerosos estudios; la mayoría de ellos concentrados en sus formas jurídicas ${ }^{1}$. Los aspectos doctrinales, el sistema de herencia y de sucesión, así como las cualidades que el derecho prescribe para esta propiedad privilegiada son ampliamente tratados por la historiografía. Del mismo modo, la incidencia de esta forma patrimonial en las estrategias de cohesión de los linajes y la compleja relación con el proceso de centralización política bajomedieval, completan el cuadro de las preocupaciones de los hispanistas ${ }^{2}$.

Este trabajo se propone una reflexión metodológica que permita profundizar en el conocimiento de un fenómeno ricamente documentado. La vasta producción sobre el tema será abordada en clave de la revisión de los supuestos con que la historiografía ha apreciado la relación entre la praxis y la expresión jurídica de esta modalidad de propiedad.

El carácter condicional de la propiedad en el feudalismo, inscripta en una densa trama de vínculos políticos, serviciales y clientelares, encuentra su punto límite con la emergencia de un tipo de bienes cuyo carácter inalienable pretende garantizar la preservación inalterable de los patrimonios ${ }^{3}$. El mayorazgo castellano expresa esta forma protegida de propiedad que, sin embargo, no implica la plena disponibilidad por su titular, limitado por la red familiar a la que pertenece. De este modo, el carácter absoluto de la disposición de los bienes se encuentra negado por las relaciones que constituyen políticamente las estructuras patrimoniales medievales.

La centralidad que asumen las prácticas políticas y económicas amplía la comprensión del mayorazgo como fenómeno estrictamente nobiliario, para situarlo dentro de las estrategias patrimoniales y de poder del conjunto de los sectores privilegiados, incluyendo a las poderosas elites de las ciudades castellanas bajomedievales ${ }^{4}$.

\footnotetext{
${ }^{1}$ La activa producción de los juristas del siglo XIX anticipa las investigaciones posteriores de los historiadores de oficio, véase SAMPERE Y GUARINOS, J.; Historia de los vínculos y mayorazgos, Madrid, Ramón Rodríguez de Rivera, 1805.

2 Devís Márquez señala que la historiografía ha priorizado el estudio del mayorazgo desde las estructuras de linaje y las prácticas hereditarias; no obstante, en un contexto de crisis y de cambio político, es el régimen patrimonial la clave que explica el fenómeno, Devís Márquez, F.: Mayorazgo y cambio político. Estudios sobre el mayorazgo de la Casa de Arcos al final de la Edad Media, Univ. de Cádiz, 1998, p. 15.

${ }^{3}$ Si bien coincidimos en la apreciación general, matizamos la idea de Aron Guriévich respecto de que «El concepto de 'propietario particular' no es aplicable en la Edad Media», GURIÉVICH, A.: Las categorías de la cultura medieval, Madrid, Taurus, 1990, p. 281.

4 Sobre estas últimas, la construcción de su poder como clase estamental demanda no sólo de estrategias materiales como la que estudiamos aquí; sino de un «esfuerzo de proyección de su condición» y de su poder que los obliga a la ostentación y a la exhibición, en tanto deben «fundamentar su situación de preeminencia sobre una base de notoriedad», GUERRERO NAVARRETE, Y., «El poder exhibido: La percepción del poder urbano. Apuntes para el caso de Burgos», Edad Media. Revista de Historia, 14 (2013), pp. 81-104, esp. 88.
} 
Si la negociación, la disputa y el acuerdo atraviesan las distintas manifestaciones de la propiedad feudal, la propiedad vinculada y sujeta al principio de primogenitura no es ajena a ellos, ni en su origen, ni en su desarrollo. Por su parte, el estudio de la adaptación de la norma a las condiciones concretas de realización de las propiedades privilegiadas posibilita advertir las contradicciones entre diversos intereses que se manifiestan en la política patrimonial de las familias prominentes ${ }^{5}$. Las leyes regias, tanto como las propias escrituras de fundación de mayorazgos ${ }^{6}$, dan cuenta de la necesidad de una constante adecuación a la compleja lógica de reproducción de estos sectores.

El mayorazgo se revela en la tensión entre una forma idealmente estable y su existencia realmente negociada ${ }^{7}$. En este punto se centra la clave de lectura tanto de la base erudita, como de los principales aportes sobre el problema. No se trata de una oposición entre el orden de lo jurídico y el universo de prácticas singulares de cada una de las casas. Por el contrario, las ambigüedades son contenidas en las disposiciones generales, así como en cada uno de los privilegios específicos. La ley y la doctrina contemplan las diversas circunstancias de los linajes, de modo que las recurrentes cláusulas de excepción terminan convirtiéndose en un mecanismo necesario a través del cual se afirma la propiedad protegida. Para que la norma pudiera aplicarse se debían observar las numerosas irregularidades que ofrecía cada situación. En suma, para salvaguardar la propiedad de una clase sobre el medio de producción fundamental, la regla debía ser lo suficientemente plástica para adecuar la protección del patrimonio del grupo, a las alternativas de cada propietario (cambios de generación, accidentes, extinción de linajes, etc.). En última instancia, se reconoce la articulación entre la sanción ordenadora del derecho emanado de un poder legítimo, a través de concesiones y cartas de privilegio, y la dinámica social, política y económica.

La capacidad de las distintas fracciones dominantes de acceder, por medio de la merced regia, a la vinculación de parte de sus patrimonios, constituye un aspecto relevante de las estrategias de la aristocracia y las oligarquías urbanas ${ }^{8}$. La

\footnotetext{
${ }^{5}$ Sobre la noción de «condiciones de realización de la propiedad», CONGOST, R.; Tierras, Leyes, Historia. Estudios sobre 'la gran obra de la propiedad', Barcelona, Crítica, 2007, pp. 148-156.

${ }^{6}$ La propiedad vinculada que se ajusta a las leyes regias y aquella que resulta de protocolos privados que establecen la no enajenación de los bienes en USUNÁRIZ GARAYOA, J. M.: «Mayorazgos, vinculaciones y economías nobiliarias en la Navarra de la Edad Moderna», lura Vasconiae, 6 (2009), pp. 383-424, esp. 388.

7 Rosa Congost señala una advertencia metodológica que hacemos nuestra: "Concebir una propiedad absoluta, es decir, "una propiedad sin intermediarios", en las relaciones entre los hombres y la tierra significa hacer abstracción de muchos individuos y de muchos derechos", en otras palabras eludir los diversos intereses que hacen al dinamismo de este fenómeno, CONGOST, R.: op. cit., p. 123.

${ }^{8}$ Las estrategias patrimoniales y la reproducción social de las elites urbanas, en BARTOLOMÉ BARTOLOMÉ, J. M; GARCÍA FERNÁNDEZ, M.: «Patrimonios urbanos, patrimonios burgueses. Herencias tangibles y transmisiones inmateriales en la Castilla interior», Studia Historica (Moderna), 33 (2011), pp. 17-28.
} 
amenaza de disgregación, producto del sistema de herencia igualitaria ${ }^{9}$, es parte sustantiva de la dinámica patrimonial de los sectores privilegiados ${ }^{10}$; si bien se elaboran fórmulas para contener las tendencias centrífugas, no siempre logran neutralizar las fuerzas dispersantes ${ }^{11}$. Los conflictos, las impugnaciones, los cuestionamientos permanentes entre los miembros de los linajes, son agudizados por una política que tiende a priorizar la línea del mayor de los herederos. En este sentido, las rivalidades por el disfrute preferencial del patrimonio, impiden la estabilización de esta forma de propiedad y en muchos casos, perturban el objetivo de concentración de las fortunas familiares.

En el conflictivo siglo XV castellano, las familias privilegiadas locales se involucran en situaciones transaccionales tanto con el poder superior, como entre sus diferentes miembros. La propiedad vinculada forma parte de esta lógica, que la torna un objeto menos estable que el pretendido en el acto jurídico de su creación.

Para un caso tardío del siglo XVIII, María Angustias Montilla García señala que la prolongada vigencia del mayorazgo hace inevitables sus transformaciones «no tanto en sus textos legales, sino en cuanto a interpretación y funcionamiento real en relación con la coyuntura de cada época» ${ }^{12}$. En el tránsito a la Edad Moderna, los cambios en «el funcionamiento real», son contemplados por la amplitud de las mismas leyes.

El mayorazgo como fenómeno patrimonial, cuyo carácter fundamental está dado por la protección de los bienes de los linajes, revela su fortaleza en la plas-

\footnotetext{
9 La herencia igualitaria estaba prescripta ya en el Fuero Real: «Si el que muriere sin manda e sin herederos naturales oviere sobrinos fiios de hermanos o de hermana por más propincuos, todos partan la buena del tío o de la tía por cabeças, maguer que los sobrinos del un hermano sean más que del otro, ca pues eguales son e en egual grado, eguales deven seer en la partición», MARTíNEZ DIEZ, G.: (ed.), Leyes de Alfonso X, II. Fuero Real, Ávila, Fundación Sánchez Albornoz, 1988, Tit. 6, Ley 13, pp. $331-332$. Las pervivencias bajomedievales del derecho visigodo a través del arraigo del Liber ludiciorum, se aprecian en la transmisión igualitaria de la herencia intestada: «Si pater vel mater intestati discesserint, sopores cum fratibus in omni parentum hereditate absque aliquo obiectu equali divisiones succedant» Liber ludiciorum, Libro IV, Tit. I. Por su parte, en las Partidas se contempla la partición de la herencia en el caso del patrimonio intestado «Muriendo el padre, o el avuelo sin testamento, o alguno de los otros que suben por la línea derecha, el fijo o el nieto que nasciesse de otro su fijo, ganan, e heredan todos los bienes del finado, quier sean varones, quier mugeres maguer aquel que murió sin testamento", Partidas, VI, Tit. XIII, Ley III; y con ciertas condiciones de los bienes incluidos en testamento: «cada uno de los herederos que ha derecho de heredar los bienes del finado, puede demandar a los otros que los partan entre sí. E pueden ser partidos estos bienes, segund manda el testador en su testamento, quando lo fizo; o si murió sin manda, deven partir la herencia del...Pero si en los bienes del testador fueron falladas algunas cosas malas...non las deben partir entre sí», Partidas, VI, Tit. XV, Ley II.

10 El papel de la herencia en la disgregación e inestabilidad del patrimonio aristocrático, en PASTOR DÍAZ DE GARAYO, E.: Castilla en el tránsito de la antigüedad al feudalismo. Poblamiento, poder político y estructura social del Arlanza al Duero (siglos VII-XI), Junta de Castilla y León, Valladolid, 1996.

11 La institución del mayorazgo serviría para contrarrestar el derecho común castellano que preveía la distribución igualitaria de las sucesiones, PICAZO, M. T.: El mayorazgo en la historia económica de la región murciana, expansión, crisis y abolición (s. XVII-XIX), Madrid, Ministerio de Agricultura, Pesca y Alimentación, 1990, p. 35

12 MONTILLA GARCÍA, M. A.: «La función de los mayorazgos en la vida social. A propósito del pleito por la herencia del de los Campillos en 1751 en la villa de Medrano", Segundo Coloquio sobre historia de La Rioja: Logroño 2-4 de octubre de 1985, Univ. de La Rioja, 1986, pp. 193-198, esp. 193.
} 
ticidad con que se configura en cada caso, acorde a los distintos intereses de los grupos dominantes. El estudio que aquí proponemos, desde una historia social del poder, pretende situar la propiedad vinculada dentro de las múltiples estrategias de los sectores privilegiados castellanos. En este sentido, se trata de reconocer un mecanismo concreto esencial de reproducción del sistema, a través de la indagación de las normativas sobre la propiedad en los siglos bajomedievales castellanos.

\section{INTERPRETACIONES SOBRE EL MAYORAZGO: TRADICIONES Y CUESTIONES DE MÉTODO}

El mayorazgo ha sido objeto prioritario de análisis de la historiografía institucionalista y en particular de los historiadores del derecho ${ }^{13}$. Por su parte, la historia social ha demostrado un menor interés por su estudio específico, recuperándose habitualmente como una herramienta jurídica más dentro de las políticas patrimoniales de las grandes casas. Es posible que ello sea resultado de la adopción de los supuestos de las primeras investigaciones, que inscribían el mayorazgo en el plano estrictamente doctrinario. Por fuera del hecho jurídico, pareciera entonces que poco había que decir sobre esta forma privilegiada de patrimonio; cuya aparición en el ámbito castellano es relativamente tardía y presenta matices respecto de otras regiones europeas ${ }^{14}$.

La vasta producción de la historia del derecho y de las instituciones comprende los numerosos estudios de caso de corte descriptivo; con escasas excepciones en las cuales se propone una interpretación de alcance general sobre el fenómeno ${ }^{15}$ El seguimiento del derrotero del patrimonio privilegiado de un determinado linaje, con las diversas coyunturas que atraviesa, las luchas internas, las alianzas y favores políticos obtenidos, así como su vínculo con los procesos de señorialización,

${ }^{13}$ GARCÍA DÍAZ, I.: «Mayorazgo y vinculación de la propiedad señorial en Murcia a fines de la Edad Media», Miscelánea Medieval Murciana, XV, (1989), pp. 139-184; BERMEJO CABRERO, J. L.:«Sobre nobleza, señoríos y mayorazgos", Anuario de Historia del Derecho Español, LV (1985), pp. 253-305, PORRAS ARBOLEDAS, P.: «Aportación al estudio del Mayorazgo. Tres ejemplos giennenses de los siglos XIV, XV y XVI», Boletín del Instituto de estudios giennenses, 139 (1989), pp. 63-97. Una crítica de la prioridad del derecho sucesorio en la constitución del mayorazgo, en USUNÁRIZ GARAYOA, J. M.: op. cit., p. 386.

${ }^{14}$ El mayorazgo castellano se diferencia de los demás casos europeos por la circulación estricta general de los bienes nobiliarios, la expresa prohibición de la enfiteusis y la imposibilidad de la monarquía de confiscarlos, GARCÍA DÍAZ, I., op. cit., p. 141; la comparación con otras áreas en CLAVERO, B.: Mayorazgo, Madrid, Siglo XXI, 1974, pp. 279-287.

${ }_{15}$ La preponderancia de los estudios de caso y la propuesta de una reflexión sobre las lógicas sociales que sostienen la política patrimonial de los distintos linajes en QUINTANILLA RASO, M. C.: «Propiedad vinculada y enajenaciones. Métodos y lógicas nobiliarias en la Castilla Tardomedieval», Historia. Instituciones, Documentos, 31 (2004), pp. 493-510, esp. 494. 
resultan los rasgos dominantes de los trabajos de corte empirista ${ }^{16}$. Si bien estas contribuciones son de indudable valor, no alcanzan a problematizar el carácter complejo del objeto, ni tampoco el proceso histórico de su conformación.

Los abundantes estudios monográficos que se concentran en la reconstrucción de los avatares de un mayorazgo en particular ${ }^{17}$; reconocen en él, una fórmula patrimonial clave de los sectores privilegiados ${ }^{18}$.

La tendencia hacia elaboraciones exhaustivamente fenoménicas importa una discusión metodológica respecto de la relación entre el derecho y el proceso social en el que se inscribe. Razones de espacio impiden hacer un balance de este amplio debate; sin embargo advertimos que entendemos aquí el hecho jurídico como práctica social y política condicionada por la cambiante y contradictoria relación de fuerzas entre los diferentes actores que componen la dinámica bajomedieval. Fundamentalmente, las tensiones surgen de las diversas alternativas que enfrentan las familias en tanto estructuras complejas, sometidas a reglas que debían adaptarse a la preservación histórica de la propiedad. De este modo, tampoco la creación legal del objeto es ajena a las disputas que atraviesan el proceso histórico, tanto en el caso de los patrimonios vinculados a través de la licencia real, como en aquellos en que se constituyen sin contar con ella. El derecho sanciona relaciones que encuentran en él la forma prioritaria de cristalización ${ }^{19}$.

El trabajo de Bartolomé Clavero es sin lugar a dudas el estudio más riguroso y sistemático, ineludible para el inicio de una reflexión sobre el problema. El autor comienza su aproximación al mayorazgo castellano desde la «constitución jurídica de la propiedad territorial laica en el área ${ }^{20}$ a partir de la gradual precisión con que el derecho dotará de sentido la existencia de este conjunto patrimonial ${ }^{21}$. No obs-

16 Entre otros PALENCIA HERREJÓN, J. R.: «Estrategia patrimonial y jerarquía del linaje: Los mayorazgos de la Casa Ducal de Maqueda en el siglo XVI», Historia. Instituciones. Documentos, 29 (2002), pp. 337-355; GARCÍA DÍAZ, I., op. cit.; MORENO NÚÑEZ, J. I., «Mayorazgos arcaicos en Castilla», En la España medieval, 5, (1984), pp. 693-706; idem, «Los señoríos de Navamorcuende, Cardiel y Villatoro, bienes vinculados. La quiebra del orden sucesorio y el mayorazgo de 1449», Documenta \& Instrumenta, 5, (2007), pp. 99-127; TELLERÍA ORBELZU, A. M.: «El señorío de Villafranca de la Sierra de Ávila: Dos diplomas medievales en el Archivo Real de la Cancillería de Valladolid», Edad Media. Revista de Historia, 4 (2001), pp. 227-232.

17 DE TORRES, J. C: «El mayorazgo fundado por Cristóbal de Piédrola y su mujer Isabel Palomino de Arjona (1525)», Boletín. Instituto de Estudios Gienenses, 202 (2010), pp. 137-204, desde una perspectiva filológica ejemplifica esta casuística.

18 El mayorazgo como «utensillo jurídico» orientado a consolidar y perpetuar los grandes patrimonios castellanos en PALENCIA HERREJÓN, J. R.: op. cit., p. 353.

19 «Sin la sanción del derecho, las relaciones sociales no tenían valor», de allí el esfuerzo compartido de los poderes feudales y la propia Corona por adaptar la norma a una realidad de la que debía dar cuenta a la vez que modelarla, GURIÉVICH, A.: op. cit., p. 189.

20 CLAVERO, B.: op. cit., p. 1.

21 El mayorazgo como institución que resulta de la «introducción de nuevos elementos jurídicos en el seno de este conjunto institucional de existencia... anterior», en CLAVERO, B., op. cit, p. 22; también MORENO NÚÑEZ, J. I.: «De nuevo sobre mayorazgos arcaicos en Castilla: El caso del llamado mayorazgo de Villanueva de Gómez (Ávila)», en DEL VAL VALDIVIESO, M. I.; MARTÍNEZ SOPENA, P.: 
tante, su obra trasciende los abordajes formales, al afirmar que «La prehistoria del mayorazgo no será, por tanto, ofrecida por la sucesión de los elementos jurídicos que entran en su composición» 22 . De allí que el interés del historiador sea reconocer «la relación social que encuentra constitución jurídica en el mayorazgo o, en su caso, en la relación jurídica que anteriormente configuraba, en un estado previo de desarrollo, dicha relación social» ${ }^{23}$.

La propiedad no se presenta como hecho dado, sino como resultado de las relaciones que la configuran como objeto histórico ${ }^{24}$. De este modo, el trabajo de Clavero supera los modelos abstractos jurídicos para dotar al fenómeno de una historicidad que nos permite inscribirlo en los desarrollos políticos y económicos de los sectores de poder bajomedievales.

Por otra parte, ha sido recurrente en la historiografía institucional vincular el régimen de mayorazgo estrechamente a las reglas de herencia y a la estructuración del sistema de parentesco nobiliario ${ }^{25}$. Sin embargo, este aspecto es revisado por Clavero para quien las múltiples modalidades que asume la transmisión de esta forma de patrimonio repelen su mecánica identificación con la sucesión por primogenitura. El autor constata que no fueron de cumplimiento estrictamente efectivo ni la herencia del primogénito varón, ni la originaria pretensión del poder concedente de imponer la cláusula de reversión del patrimonio otorgado al producirse la muerte del concesionario; a la vez que advierte acerca de las diversas circunstancias consideradas por las leyes que ameritaban la quita de los bienes vinculados $^{26}$.

La conformación legal del mayorazgo implica tanto la licencia regia como las condiciones que establece el fundador para la vigencia del privilegio, aún sin contar con la autorización del soberano. La distancia entre la intención fundacional y la realidad efectiva de este tipo de patrimonio se expresa en la evolución que experimenta entre los siglos XIII y XVI, de la que dan cuenta los mismos cuerpos legales que lo definen. De este modo, el estudio de la institución trasciende el nivel

Castilla y el mundo feudal. Homenaje al Profesor Julio Valdeón, Junta de Castilla y León, Univ. de Valladolid, 2009, pp. 375-385, esp. 380.

22 CLAVERO, B: op. cit., p. 52.

23 Ídem.

24 «habrá de tenerse en cuenta, una vez más, que el hecho jurídico no es inmediatamente el hecho histórico, o, dicho de otro modo, que el testimonio del derecho no puede reclamar exclusividad de la historia institucional. La tipicidad del objeto de mayorazgo vendrá determinada por la adecuación económica entre una clase de propiedad y el régimen jurídico vinculado; dicha adecuación por ser un presupuesto del derecho, no necesita ser formulada por el mismo", Ídem, p. 261.

${ }^{25}$ Al respecto, BECEIRO PITA, I; CÓRDOBA DE LA LLAVE, R.: Parentesco, poder y mentalidad. La nobleza castellana: Siglos XII-XV, Madrid, CSIC, 1990; HERNÁNDEZ FRANCO, J.; MOLINA PUCHE, S.: «Mantenerse arriba. Las familias dominantes en la Castilla moderna", en CHACÓN JIMÉNEZ, S.; HERNÁNDEZ FRANCO, J. (eds), Espacios sociales, universos familiares. La familia en la historiografía española, Murcia, 2007, pp. 219-244.

${ }^{26}$ La traición, el crimen de lesa majestad y el pecado de homosexualidad son algunas de las excepciones contempladas, CLAVERO, B.: op. cit., p. 267. 
de la concesión formal para reconocer las variables situaciones que cada acto de creación debía contemplar.

Los aportes más recientes coinciden en situar el fenómeno dentro de la construcción de la memoria de los grandes linajes, como parte de las estrategias de cohesión y afianzamiento de las familias que encuentran en este régimen de disposición de las fortunas un medio eficaz para exhibir la conciencia simbólica de las parentelas ${ }^{27}$. En este sentido, la constitución de los mayorazgos castellanos, explorada desde una historia social del poder de los segmentos privilegiados resulta hoy un campo revitalizado de la reflexión historiográfica.

\section{PROPIEDAD PRIVILEGIADA Y RELACIONES DE PODER}

La sustitución fideicomisaria romana aparece como el antecedente más remoto de este tipo de propiedad, cuyas manifestaciones tempranas encontramos en los patrimonios sometidos a un orden de sucesión por el principio de primogenitu$\mathrm{ra}^{28}$. Ya en las Siete Partidas se anticipa el reconocimiento del derecho del descendiente mayor en el caso de la sucesión del reino ${ }^{29}$, así como la posibilidad de sustituir al heredero en el de los bienes recibidos por testamento ${ }^{30}$. A finales del siglo XIV, el mayorazgo aparece como institución peculiar castellana que cumple un papel clave en la consolidación del patrimonio territorial feudal ${ }^{31}$. Sin embargo, son las Leyes de Toro de 1505 el punto de llegada de la larga evolución medieval de esta forma patrimonial.

A partir de un pormenorizado estudio de legislación y jurisprudencia, se sintetizan las cualidades del régimen de mayorazgo plenamente consolidado como «régimen patrimonial del dominio señorial y eminente de la tierra» ${ }^{32}$; entre ellas se destacan: la unidad de tierras y de derechos geográficamente dispersos, la estricta prohibición de toda forma de enajenación y enfiteusis -incluso por parte de la

${ }^{27}$ Entre otros, ORTEGA CERVIGÓN, J. I.: «Nobleza y poder en la Tierra de Cuenca: Nuevos datos sobre el linaje Albornoz», Miscelánea medieval murciana, XXXIII (2009), pp. 143-173, esp. 154 y RUIZ PILARES, E: «El mayorazgo del veinticuatro Pedro Camacho de Villavicencio "el rico" (1507) El patrimonio del caballero jerezano más acaudalado de su tiempo", En la España Medieval, 35, (2012), pp. 317-347, esp. 327. La participación del mayorazgo dentro de las «vivencias del linaje» en SÁNCHEZ SAUS, R.: «Los patriciados urbanos», Medievalismo, 13-14 (2004), p. 149.

28 CLAVERO, B.: op. cit., p. 22.

29 A propósito de la adquisición del señorío real, se prescribe entre una de las formas de derecho para ser «llamado rey... cuando por herencia hereda los reinos el hijo mayor»; no obstante, también se contempla la ampliación en la línea sucesoria de «algunos de los otros que son más cercanos parientes de los reyes al tiempo de su muerte», Partidas, II, Tit I, Ley IX.

30 «Establezco a fulano por mio heredero, e si el non quisiere, o non lo pudiere ser, sealo fulano en lugar del», Partidas, VI, Tit. V, Ley I.

${ }_{31}$ MARCOS MARTÍN, A.: «Estructuras de la propiedad en la época moderna: evolución y variantes peninsulares», en Robledo Hernández, R.; Torijano Pérez, E. et al. (Coords), Historia de la propiedad en España. Siglo XV-XX, Salamanca, 1998, pp. 113-162, esp. 121.

32 CLAVERO, B.: op. cit., p. 48. 
propia monarquía-, su carácter perpetuo, vinculado y la trasmisión sucesoria como parte de la integración a los patrimonios aristocráticos.

Desde la perspectiva de la doctrina jurídica, el mayorazgo se vincula al derecho sucesorio a partir de la imposición del régimen de primogenitura; de allí que en la definición de Luis de Molina, ambos conceptos aparezcan como sinónimos ${ }^{33}$.

Leyes generales del reino en las que se afirma la doctrina sobre la propiedad privilegiada, numerosas cartas de fundación de mayorazgo con o sin licencia regia y diversos pleitos por la vigencia de los mismos conforman la base documental de las diferentes elaboraciones. Esta realidad patrimonial se expresa en un conjunto de prescripciones que involucran las reglas de sucesión y que tienen como objetivo asegurar la integridad del poder material y el arraigo social de los principales linajes.

Sin embargo, este intento de resguardo de las fortunas promueve, como se ha señalado, una serie de conflictos que revelan el dinamismo y la complejidad de los intereses involucrados. La variada casuística que se aprecia en los numerosos pleitos expresa la heterogeneidad de las regulaciones sobre el patrimonio ${ }^{34}$; a la vez que señala la centralidad de las estrategias de reproducción de los segmentos privilegiados en la determinación del propio objeto jurídico ${ }^{35}$.

En este sentido, la norma se presenta habitualmente como resultado de la creación de los poderes superiores, mientras que los enfrentamientos que su aplicación desata, darían cuenta de las resistencias que ofrece el sistema de herencia igualitario ante las modificaciones de la herencia testada. Sin embargo, esas contradicciones inciden en la propia elaboración de las prescriptivas, al punto que las leyes mismas contemplan las circunstancias variables que niegan su orientación fundamental. Si «la doctrina mayorazguista desarrolló una amplia casuística» ${ }^{36}$, en la inclusión del caso particular dentro de la regla general se manifiesta un atributo sustantivo del fenómeno.

Hemos mencionado ya que existen situaciones en las cuales la constitución del mayorazgo, aún dependiendo «en última instancia» de la licencia real, no es producto de una inicial autorización del soberano, sino que su acción legitimadora es posterior a la conformación de un importante patrimonio vinculado. Éste es el caso del señorío murciano de Cotillas estudiado por García Díaz: «Nos encontramos, pues, ante un mayorazgo sin fundación, que no existe de derecho, aunque el nuevo titular, Ferrán Carrillo, mantendrá la ficción del mayorazgo de hecho e inten-

${ }^{33}$ DE MOLINA, L: De Hispanorum primogeniorum origine ac natura, Lugdunum, 1613.

${ }^{34}$ CARMONA RUIZ, M. A: «La mentira como arma. Pleitos en torno a la propiedad de un mayorazgo. Nínchez y Chozas (ss. XV y XVI)", Historia. Instituciones. Documentos (2009), pp. 111-136, esp. 111 y 124.

${ }_{35}$ Las normas sucesorias como elemento esencial de los mayorazgos bajomedievales, en GARCíA DÍAZ, I., op. cit., p. 162.

${ }^{36}$ MORENO NÚÑEZ, J. I: «Los señoríos de Navamorcuende», p. 109. 
tará consolidarlo de derecho» ${ }^{37}$. De esta circunstancia que se opone a la legislación imperante, se deduce la causa de los numerosos litigios que se originan por esos bienes a lo largo de las últimas dos décadas del siglo XV. La prevalencia que se otorga al derecho como fuente creadora de las relaciones entre los hombres y la tierra se inscribe en un análisis formal de una realidad compleja, en la cual el recurso a la ley suele ser también un arma en la lucha por afianzar las posiciones de poder ${ }^{38}$.

No obstante el interés de su trabajo, las conclusiones de García Díaz son representativas de una visión de la cual tomamos distancia en estas páginas: en Murcia, pese a los reiterados ejemplos expuestos, el mayorazgo no ha logrado imponerse. La debilidad de los propietarios aristocráticos para obtener la vinculación de algunos de sus bienes residiría en «que las condiciones del mayorazgo están en contradicción con el derecho» ${ }^{39}$. Sin embargo, el derecho se nos revela como una elaboración mucho más plástica que contempla, en un delicado juego de intereses, la multiplicidad de situaciones.

\section{LAS LEYES DE TORO: LA EXCEPCIÓN HACE A LA REGLA}

En las Cortes de 1505 se promulga un conjunto de normas sobre distintas cuestiones civiles, dentro de un nuevo intento de unificación jurídica del reino ${ }^{40}$. El objetivo de la Corona es homogeneizar la acción legislativa para fortalecer su potestad imperativa. Dentro de este programa encontramos la más acabada formulación legal de la propiedad vinculada y el sistema de sucesión aristocrática.

En el contexto de la compleja construcción del estado centralizado, se presta especial atención a los asuntos relacionados con las reglas de reproducción de los sectores dominantes. Así es como la herencia de los linajes, la situación de la mujer respecto de los bienes de las familias y los propios testamentos son objeto de minuciosas reglamentaciones. En este marco, se encuentran las leyes que regulan el régimen de mayorazgo, estableciendo una serie de precisiones sobre las condiciones de su fundación y permanencia.

Se ordena que Los ascendientes legitimos, por su orden e linea derecha, sucedan ex testamento e ab intestato a sus descendientes y les sean legitimos he-

37 GARCÍA DÍAZ, I.: op. cit., p. 144 (destacado nuestro).

${ }^{38} \mathrm{La}$ adquisición inicial de heredades, los matrimonios de prestigio y la obtención de rentas reales, forman parte de las estrategias de acrecentamiento patrimonial de miembros destacados de la oligarquía murciana, que encuentran en el mayorazgo un eficaz recurso para la consolidación del linaje, Idem, pp. 148-149. Advertimos situaciones similares para el caso de Ávila.

39 Ídem, p. 164.

40 Desde la perspectiva jurídica, BERMEJO CASTRILLO, M. A., «Las leyes de Toro y la regulación de las relaciones familiares", en GONZÁLEZ ALONSO, B. (Coord.), Las Cortes y las Leyes de Toro de 1505 Actas del Congreso conmemorativo del V centenario de la celebración de las Cortes y de la publicación de las Leyes de Toro de 1505, Cortes de Castilla y León, 2006, pp. 383-548. 
rederos ${ }^{41}$; a la vez que se contempla que en la tercia parte de sus bienes puedan disponer los dichos descendientes en su vida o fazer cualquier ultima voluntad ${ }^{42}$. No obstante, la política regia expresada en este cuerpo legal debe adecuarse a las particularidades de cada lugar; de allí que se precise: salvo en las ciudades e villas e logares do, según el fuero de la tierra, se acostumbran tornar los bienes al tronco o la rayz ala rayz ${ }^{43}$.

Las diferentes circunstancias que se consideran para legitimar la creación y la conservación de los mayorazgos señalan la flexible relación entre la norma y los diversos intereses políticos y económicos presentes en cada caso. En este sentido, las ambivalencias que se observan en este conjunto normativo no son producto de inconsistencias o debilidades del legislador; sino por el contrario, de su habilidad para reconocer las necesidades de los sectores de poder. El seguimiento en detalle de estas oscilaciones permite advertir el dinamismo que importa la construcción legal del objeto.

La monarquía contempla las variables posibilidades de realización de la propiedad privilegiada dentro de un proceso de negociación con los poderes privados, cuyas estrategias de reproducción debe condicionar tanto como favorecer.

La prelación de la autorización regia manifiesta la intención subordinante del monarca: que la licencia del rey para fazer mayorazgo preceda al fazer del mayoradgo, de manera que aun quel Rey de licencia para fazer mayorazgo por virtud dela tal licencia no le confirme el mayoradgo que de antes estuviere fecho ${ }^{44}$.

Este pasaje de la ley pareciera ser contundente en cuanto a la afirmación de la prioridad del soberano; sin embargo, como sucede a lo largo de todo el Ordenamiento, se incorporan cláusulas de excepción que corrigen el propósito original. Prosigue la misma ley: salvo sy enla tal licencia espresamente se dixese que aprovava el mayoradgo que estava fecho ${ }^{45}$. La Corona se reserva la potestad de validar la existencia de bienes vinculados creados con anterioridad ${ }^{46}$.

De esta política de concesiones graduales se deriva la legitimación de la facultad para fundar mayorazgo sobre casi la mitad del patrimonio, sin requerir de la licencia regia ${ }^{47}$. Se trata de los llamados mayorazgos «por vía de mejora» que

${ }^{41}$ Cortes de León y Castilla, Madrid, Real Academia de la Historia, T. IV, 1882, Leyes de Toro, 6, p. 200.

42 Ibídem.

43 Ibídem.

44 Ibídem.

45 Ibídem.

${ }^{46}$ Para el caso abulense: «Por quanto vos el comendador Françisco de Avila, vezino de la çibdad de Avila, nos fezystes relaçión que queríades fazer e ordenar un mayoradgo de las nuestras casas que vos teneys en la dicha çibdad e de los heredamientos que tenéys en Riofrío... E es nuestra merçed e voluntad que el dicho mayoradgo vala e sea firme non enbargante qualquier ley o derecho que le pueda ynpedir espeçialmente syn enbargo de las leyes, fueros e derechos que quiren que ninguno non pueda dar nyn donar todo lo suyo», HERRÁEZ HERNÁNDEZ, J. M.: Documentación abulense Registro General del Sello, vol. X, Gran Duque de Alba, Ávila, 1996, Doc 94 (1494), p. 161.

47 CLAVERO, B.: op. cit., p. 223. 
contemplan los derechos de los herederos legítimos y señalan la capacidad de los linajes para asegurar la conservación y engrandecimiento de sus fortunas:

cuando el padre o la madre mejoraren a alguno de sus hijos o descendientes legítimos en el tercio de sus bienes en testamento o en otra cualquier última voluntad o por contrato entre vivos, que le puedan poner el gravamen que quisieren, así de restitución como de fideicomiso, e facer en el dicho tercio los vínculos e sumisiones e sustituciones que quisieren ${ }^{48}$.

Las condiciones que hacen a la legitimidad de la disposición de la propiedad vinculada se encuentran previstas por la normativa. En ella se incluyen las tres fórmulas probatorias habituales, escritura —que en este caso se corresponde con la licencia regia-, testimonios y costumbre:

quel mayoradgo se pueda provar por la escritura dela institución del con la escritura dela licencia del Rey quela dio...o por los testigos que depongan en la forma quel derecho quiere...e asy mismo por costumbre inmemorial provada con las calidades que concluya los passado aver tenido e poseydo aquellos bienes por mayoradgo ${ }^{49}$.

El derecho interviene preservando usos, modifica sin alterar de raíz el contenido de la forma.

El proceso de negociación por el cual se legitima el carácter privilegiado de las propiedades importa un conjunto de estrategias que hacen a la construcción de las posiciones de poder. Los efectos de la manipulación de la costumbre y de la movilización de las redes clientelares como testigos favorables en los distintos pleitos señalan el éxito de esta intervención política de los grandes.

Si bien la potencia de las estrategias de reproducción de las estructuras parentales se aprecia en el margen decisional que se arrogan sus titulares ${ }^{50}$; la Corona no cede completamente la iniciativa. Por el contrario, en la nueva conformación de la propiedad privilegiada y en el diseño de las reglas de sucesión, se expresa la tensión entre la potestad regia y el necesario diálogo con los poderes particulares ${ }^{51}$. La dimensión transaccional aparece no sólo en la aplicación con-

48 Leyes de Toro, 27, p. 205 (destacado nuestro).

49 La importancia que en la citada ley se otorga a la costumbre se enmarca en los habituales procedimientos probatorios medievales: «que lo testigos sean de buena fama: e digan que ansi lo vieron ellos passar por tiempo de cuarenta años: e asy lo oyeron dezir asus mayores e ancianos que ellos siempre asy lo vieran e oyeran que nunca vieron ni oyeron dezir lo contrario e que dello es publica boz e fama e comun opinión entre los vezinos y moradores dela tierra», Leyes de Toro, 41, p. 209.

50 A partir de 1505 la licencia real sólo aparece como condición ineludible cuando la vinculación del patrimonio afecta la herencia de los demás herederos, contrariando la legítima, CLAVERO, B.: op. cit., pp. 222-223.

51 Tomamos distancia de la idea de una limitación de la voluntad de los testadores, como consecuencia de la fortaleza de los sistemas sucesorios distributivos que condicionarían la plena expansión de la propiedad vinculada en Castilla, sostenida entre otros por CATALÁ SANZ, J. A.: «Integridad patrimonial, 
creta de las normas generales, sino que atraviesa la evolución y transformación de las leyes mismas.

La búsqueda de equilibrios con los grandes propietarios nobiliarios y villanos orienta la actuación cuidadosa del poder regio. Así se aprecia en la reiterada cláusula ampliatoria de la regulación. La excepción es contemplada como elemento inherente a la constitución jurídica de esta propiedad: salvo sy es el recurso semántico que permite considerar la casuística, a la vez que dar cuenta de una realidad dinámica.

El supremo legislador de 1505 al sancionar la excepcionalidad, no sólo leía las múltiples situaciones de hecho creadas en torno de esta forma patrimonial, sino que al incorporarlas al texto normativo, procuraba imponerse sobre ellas, recuperando su imperio ${ }^{52}$. En otras palabras, aún cuando la ley originaria es visiblemente contrariada, las circunstancias irregulares son subsumidas por la voluntad política de la monarquía. Frente a las excepciones que se imponen como hechos concretos, el rey las autoriza al flexibilizar la norma, en pos de afirmar su propia eficacia.

A propósito de las condiciones sucesorias, tantas veces invocadas como el elemento determinante de esta forma patrimonial, veamos la formulación que presentan las Leyes de Toro. En primer lugar, se enuncia el principio de primogenitura, con el consiguiente orden de descendencia legítimo: de manera que siempre el fijo e sus descendientes legitimos por su orden representen la persona de sus padres ${ }^{53}$; para luego aceptar que salvo sy otra cosa estuviere dispuesta por el que primeramente constituyo e ordeno el mayoradgdo que en tal caso mandamos que se guarde la voluntad del quelo instituyo ${ }^{54}$. La voluntad superior del soberano considera, reconoce y sanciona las voluntades particulares de los propietarios $^{55}$.

perpetuidad, memoria. Contradicciones de los mayorazgos valencianos en la época moderna, Studia Historica (Moderna), 33 (2011), pp. 61-95, esp. 64.

${ }_{52}$ Al señalar que la administración de justicia está indisolublemente ligada al poder, Paolo Prodi afirma que progresivamente «el derecho deja de ser anterior al Estado y la ley no puede ser sometida a juicio sino que debe ser aceptada como emanación del legislador supremo", PRODI, P.: Una historia de la justicia. De la pluralidad de fueros al dualismo moderno entre conciencia y derecho, Bs. As., Katz Editores, 2008, pp. 148-149. Sin embargo, consideramos que para garantizar su eficacia, debe ser lo suficientemente flexible como para incluir la diversidad de situaciones particulares que debe enfrentar.

53 Leyes de Toro, 40, p. 209.

54 Ibídem.

55 Ya las Siete Partidas consideraban las «condiciones» que el testador puede establecer respecto de su herencia: «entre aquellas condiciones que ponen los hombres señaladamente en sus testamentos, de ellas hay que pertenecen al tiempo pasado, y otras al tiempo presente, y otras, el tiempo que es por venir... de las que no pueden ser, tales las hay que no se pueden cumplir por impedirlo la naturaleza, y tales hay que las impide el derecho; y otras, que resultan imposibles de hecho, y otras hay que no pueden ser, porque son dudosas u oscuras. $Y$ de las condiciones que pueden ser, algunas hay de ellas que están en poder de los hombres para cumplirlas, y hay otras que están en ventura si serán o no», Tit. 4, Ley 1. Se reconoce al mismo tiempo el margen de acción del individuo respecto de su patrimonio y sus límites. En este sentido, se anticipa la «confluencia de las regulaciones previas» de las que «nace lentamente lo que se definió como ius publicum moderno, un derecho que tiene sus raíces en el Estado y que del Estado emana, creando una esfera pública en la que también los derechos privados 
Así se advierte también respecto de la revocabilidad del mayorazgo, constituido con o sin la autorización regia: El que fiziere algun mayoradgo, aunque sea con autoridad nuestra o de los reyes que de nos vinieren...puedalo revocar a su voluntad $^{56}$. Sin embargo, la capacidad decisional reconocida a los fundadores se encuentra limitada, ya que la reversión de la concesión es posible salvo sy el que lo finiere...oviere entregado la posesión dela cosa o cosas contenidas enel dicho mayoradgo a la persona en quien lo finiere...o le oviere entregado la escritura dello ante escrivano ${ }^{57}$. En estos casos, el rey manda «que no se pueda revocar»; pero introduce una excepción dentro de la excepción misma: salvo sy en el poder de la licencia quel rrey le dio, estuviese cláusula para que después de fecho lo pudise revocar ${ }^{58}$ o bien que el quelo ynstituyó reservase enla misma escritura que fizo del dicho mayoradgo, el poder para lo revocar ${ }^{59}$.

Las leyes dan cuenta de la capacidad de los sectores de poder para proteger la riqueza familiar y de la habilidad estratégica para consolidar sus posesiones como propiedades perpetuas frente a las pretensiones de otras facciones de la aristocracia, incluido el linaje que ocupa el trono. De este modo, se advierte el dinamismo que tiene esta forma de propiedad sujeta a un complejo proceso de construcción ${ }^{60}$.

La creación, la permanencia y las transformaciones del mayorazgo se encuentran determinadas por las necesidades de reproducción de los sectores privilegiados, en un contexto en el cual aparecen nuevas lógicas productivas y políticas. La fundación con o sin licencia de los reyes, la selección de los bienes que se incorporan a este régimen patrimonial, las formas de transmisión sucesoria, las modificaciones que sufren los mayorazgos - y que dan lugar a la enajenación de parte de ellos- no se encuadran en un modelo jurídico absoluto. Por el contrario, todos estos elementos se encuentran condicionados por las variables estrategias desarrolladas para enfrentar las coyunturas cambiantes. En última instancia, la singularidad del mayorazgo radica menos en su pertenencia a un régimen legal general exclusivo y uniforme que en la capacidad de sus fundadores para establecer las condiciones de preservación y acrecentamiento de los patrimonios familiares.

Los principios de inalterabilidad, indivisibilidad e inalienabilidad de los mayorazgos quedaban en la práctica alterados «como consecuencia del principio de acumulación inherente» ${ }^{61}$. Las múltiples salvedades que habilita la ley -como inteligente reconocimiento por parte de la monarquía de la diversidad de las reali-

e individuales están en cierto modo acotados y regulados", P. PRODI, op. cit., pp. 143-144 (destacado en el original).

${ }^{56}$ Leyes de Toro, 44, p. 210.

57 Ibídem.

58 Ibídem.

59 Ibídem.

60 La capacidad de los titulares de mayorazgos para introducir modificaciones que resultaban en la enajenación de los bienes es advertida por QUINTANILLA RASO, M. C.: op. cit.

61 Ídem, p. 494. 
dades de hecho- refuerzan el poder de las estructuras parentales y dan cuenta de las estrategias patrimoniales que se adaptan a las necesidades de cada casa. A su vez, muchas de las licencias que la Corona otorga o se ve obligada a conceder responden a las urgencias financieras generales del reino y del bloque de poder en su conjunto. Así se advierte en las autorizaciones dadas por los soberanos para eludir la inalienabilidad de estos patrimonios con el objetivo de obtener mayor liquidez en momentos de crisis $^{62}$.

Los cambios en la legislación entre las últimas décadas del siglo XIV y los primeros años del XVI revelan las transformaciones de la relación entre los diferentes poderes feudales. Sin dudas la cláusula de reversión a la Corona -que aseguraba, en determinadas circunstancias, la recuperación por el realengo de los bienes bajo mayorazgo - ha generado intensos conflictos entre los parientes. La interrupción de la línea de sucesión legítima, por extinción biológica o bien por comisión de delitos que impidan la disposición del privilegio, son los dos principales motivos que desatan debates entre los miembros del linaje ${ }^{63}$. Se impone allí una nueva condición excepcional que tiende a garantizar el patrimonio familiar por sobre la propiedad de la persona ${ }^{64}$.

Sobre este aspecto, ya las Cortes de Guadalajara de 1390, en un contexto de compleja negociación entre el poder regio y la nobleza, habían previsto la transmisión a las líneas colaterales en caso de muerte del titular sin descendientes directos ${ }^{65}$.

La voluntad del individuo, dentro de los márgenes previstos por las leyes, se manifiesta como el principio activo de la organización de las estrategias patrimoniales y hereditarias de cada familia. Así se contempla en el destino del tercio de libre mejora, por medio del cual se concede a uno de los hijos legítimos una parte de los bienes. La posibilidad de revocar esa mejora está asegurada, aunque se

\footnotetext{
62 Ídem, p. 498.

63 «Quel condenado por delicto a muerte civil o natural pueda fazer testamento...como sino fuese condenado, el qual condenado y su comissario puedan disponer de sus bienes, salvo delos que por el tal delito fueren confiscados", Leyes de Toro, 4, p. 200.

${ }^{64} \mathrm{Al}$ respecto, «Se crea la ficción de que el poseedor del mayorazgo nunca puede cometer tales delitos", de modo que se castiga a la persona pero se protege la memoria del linaje, RUIZ PILARES, E: op. cit., p. 339.

65 Las demandas de la nobleza que culminan con la concesión a las líneas colaterales se expresan en las Cortes de Guadalajara de 1390. MITRE FERNÁNDEZ, E.: «Las Cortes de Guadalajara de 1390 en el marco de la crisis política del siglo XIV", Wad-al-Hayara: Revista de estudios de Guadalajara, 18 (1991), pp. 241-250, esp. 247. «el rey don enrique, vuestro padre, después destos donadíos fechos, fizo una cláusula en el su testamento secretamente, en que declaró que los tales donadíos de villas e logares e heredades que él fizo a los señores e caballeros... fuesen mayorazgos, e que los oviese el fijo o fija mayor e sus descendientes legítimos. E por quanto non fabla la cláusula que tornen a los transversales, que son hermanos e tíos e sobrinos, algunos entienden la cláusula muy rigurosamente, en lo qual, señor, nos tenemos por muy agraviados», LÓPEZ DE AYALA, Pero, Crónicas, Barcelona, Planeta, 1991, Cap. XIV, p. 691.
} 
reconoce una serie de situaciones que limitan al testador ${ }^{66}$. En algunos casos se contempla la misma vinculación de las propiedades incluidas en la mejora, con lo cual la relación entre reglas de sucesión por primogenitura e instauración del régimen de mayorazgo no es lineal ni ineludible.

En el cuerpo legal que reglamenta su vigencia se advierten dos principios contrapuestos: la protección del patrimonio del linaje, frente a la igualdad de los hijos en la herencia ${ }^{67}$. En este sentido, el interés del grupo se halla en tensión con las necesidades de reproducción de sus miembros individuales ${ }^{68}$. En la medida en que cada uno de ellos no encuentre otras fuentes de sostenimiento, y en ocasiones para poder acceder a ellas, la fortuna familiar será objeto de recurrentes enfrentamientos que ponen límite a la capacidad de decisión de los propietarios individuales ${ }^{69}$.

Si el mayorazgo está permanentemente amenazado por las rivalidades que su misma instauración genera, los peligros que se yerguen sobre él surgen de las propias contradicciones de la lógica de reproducción de los segmentos privilegiados $^{70}$. Este aspecto se vincula directamente con las modalidades que asume la dinámica del poder en Castilla.

\section{PROPIEDAD VINCULADA Y DINÁMICA DE CONSTRUCCIÓN $D E P O D E R$}

La tensión constante entre la colaboración, que se advierte en las concesiones que la Corona otorga para establecer alianzas con los poderes locales y la competencia, para evitar que los mismos se conviertan en una amenaza para su imperio, atraviesa la organización política del reino. La propiedad privilegiada no puede ser ajena a este proceso de disputa entre la monarquía y los poderes locales de distinto rango.

\footnotetext{
66 «Quando el padre o la madre mejorare a alguno de sus fijos o descendientes legitimos enel tercio de sus bienes en testamento...lo pueda revocar quando quisiere, salvo, si la fecha la dicha mejoría... oviere entregado la possesion dela cosa», Leyes de Toro, 17, p. 203.

67 Este principio aparece en la expresa prohibición de la donación de la totalidad de los bienes que establecen las leyes de 1505, Leyes de Toro, 69, p. 214. La reforma legislativa se inscribe en una fuerte tradición castellana de protección de los parientes que ya está presente en el citado Fuero Real: «todo omne que oviere fiios o nietos <o dent ayuso> de mugier de bendición, non puedan heredar con ellos otros fiios que aya de barragana, mas del quinto de su aver mueble e raýz puédales dar lo que quisiere», Tit. 6, Ley 1, p. 326.

68 Los bienes de la propiedad vinculada, acumulados y transmitidos por generaciones corresponden al linaje y no pueden ser gestionados como patrimonio personal, QUINTANILLA RASO, M. C.: op. cit, p. 493.

69 Las Partidas contemplaban las rivalidades que la partición de la herencia generaba en el seno de las familias: «Ca se tiran por ella desacuerdos muy grandes, que nascen entre los omes a las vegadas, por razón de las cosas que han de so uno», Partidas, Sexta Partida, T. III, Tit. XV, ley 1.

${ }^{70} \mathrm{La}$ descripción de los «peligros para la integridad de los mayorazgos» valencianos, en CATALÁ SANZ, J. A.: op. cit., p. 67.
} 
La constitución de los mayorazgos se inscribe en una política más amplia de expansión y consolidación de los linajes privilegiados, que incluye la implantación de núcleos señoriales de desigual jerarquía ${ }^{71}$. Si bien la propiedad vinculada no importa el ejercicio del poder coactivo sobre los tributarios, revela el papel que la acumulación patrimonial juega en la dinámica de poder de los siglos bajomedievales ${ }^{72}$.

La incorporación de bienes dentro de este tipo privilegiado dará impulso al crecimiento de muchas familias, algunas de los cuales, procedentes de la caballería urbana, gradualmente se incorporan a las filas de la baja nobleza local ${ }^{73}$. En este sentido, las disputas por acceder a bienes no sujetos a la condicionalidad de la propiedad feudal, son parte sustantiva de la existencia del mayorazgo castellano ${ }^{74}$.

La instauración de mayorazgos suele generar reclamos entre los herederos marginados por las cláusulas testamentarias restrictivas. Por un lado, las demandas giran en torno de la prohibición expresa de vender, empeñar y enajenar los bienes; por otro, la preocupación que ante la muerte sin descendencia del titular del mayorazgo torne el donadío a la corona real ${ }^{75}$. No obstante, en el largo desarrollo, hallamos situaciones inversas: se trata de la obtención de concesiones regias que, dentro del balance de fuerzas entre la Corona y las distintas facciones dominantes, suprimen la tan controversial condición de reversión a la monarquía ${ }^{76}$.

71 El acceso de determinados caballeros al rango señorial puede apreciarse en la concesión de Juan II a Fernand Nieto en Ciudad Rodrigo: «yo fize merced para siempre jamás a Ferrand Nieto, mi vasallo e guarda, de la juridiçión et justiçia çevil e criminal, mero e misto imperio... por vertud del qual diz quél tomó la posesión de la dicha jurisdicción e puso sus forcas en los dichos lugares», BARRIOS GARCÍA, A.; MONSALVO ANTÓN, J. M.; DEL SER QUIJANO, G., Documentación medieval del Archivo municipal de Ciudad Rodrigo, Ed. Diputación de Salamanca, 1988, Doc 282, 1440, p. 319. Véase también MORENO NÚÑ̃Z, J. I., «El caballero abulense Fernan Blázquez y el nacimiento de un señorío toledano a principios del siglo XIV: San Román del Monte», En la España Medieval, 23 (2000), pp. 117-135.

72 El rango patrimonial especialmente elevado de la caballería abulense, en contraste con la situación de otras ciudades castellanas, resulta de un patrón de conducta general tendiente a la adquisición de heredades y al acceso a la propiedad privilegiada, MONSALVO ANTÓN, J. M., «Pobladores, caballeros, pecheros y señores. Conflictos sociales en el concejo de Ávila (ss. XII-XV)», en García Fitz, F.; Jiménez Alcázar, J. F. (Coords), La historia peninsular en los espacio de frontera. La «Extremadura Histórica» y la «Transierra» (siglos XI-XV)», Cáceres, Edit. Um., 2012, pp. 375-426, esp. 401-402.

${ }^{73} \mathrm{El}$ caso de algunos de los miembros del linaje de los Dávila es representativo de esta trayectoria, Moreno Núñez, J. I: Ávila y su Tierra en la Baja Edad Media (siglos XIII-XV), Junta de Castilla y León, 1992. Sobre la simbiosis entre algunos caballeros urbanos y la nobleza, DÍAZ DE LA GUARDIA Y LÓPEZ, L.: «El poder feudal como origen de la hidalguía en la baja Edad Media castellana», Espacio, Tiempo y Forma. Serie III, Historia Medieval, 18 (2005), pp. 129-168.

${ }^{74}$ Así se advierte en el citado estudio de GARCÍA DÍAZ, I: op. cit., «Nos encontramos ante un mayorazgo sin fundación, que no existe de derecho, aunque el nuevo titular... mantendrá la ficción del mayorazgo de hecho e intentará consolidarlo de derecho», p. 144.

75 «dicen que se entiende la cláusula que el rey vuestro padre fizo, que el otro fijo o fija su hermano, non le aya, e que torne el donadío a la corona real. E, señor, esto es aún mayor agravio, que yo que laceré, e trabajé, e perdí hermanos e parientes, e derramé mi sangre por servicio del rey vuestro padre, e él, por me facer merced me heredó e me dio un donadío», LÓPEZ DE AYALA, Pero, Crónicas, Cap. XIV, p. 692.

76 Durante el reinado de Juan II, «se impone la conversión de las tierras de la Corona en mayorazgos de los señores en cuanto la renovación de la tenencia se convierte en derecho de sucesión vincular», CLAVERO, B.: op. cit, p. 35. 
Mientras que en las fases de expansión del sistema, estas tensiones se resolvían con la emigración de los segundones, en la fase final de la Edad Media, las mismas quedaban apresadas dentro de las propias familias, con el consiguiente potencial conflictivo que aparejaban ${ }^{77}$.

La mediación entre la voluntad del legislador y las múltiples modalidades de existencia de esta propiedad privilegiada se encuentra en las relaciones de poder y la trama estratégica que vincula al estado central con los núcleos políticos locales. En la dinámica política que se establece entre cada concejo o señorío y el vértice superior del reino encontramos las determinaciones particulares que inciden en las diferentes expresiones del mayorazgo. En este sentido, no se trata de una forma unívoca ni homogénea, sino que remite a las diversas condiciones tanto de creación como de permanencia. La trayectoria histórica de este tipo de patrimonio depende, por tanto, del cambiante equilibrio entre los distintos segmentos dominantes.

La impronta del poder y de la fuerza no sólo se exhibe en los procesos de negociación que permiten a determinadas familias ganar el privilegio regio; como se advierte en diferentes concejos, la imposición de condiciones que garantizan la integridad de algunos bienes forma parte de las prácticas habituales de los sectores privilegiados castellanos. En ocasiones, los personajes principales apelan tanto a la violencia como a la inevitable negociación con el resto de los herederos ${ }^{78}$.

Las fricciones se generalizan cuando el mayorazgo, hacia el siglo XV, se difunde como una forma patrimonial a la que pretenden acceder las gentes medianas $^{79}$, dentro de las estrategias de construcción de posiciones de supremacía de las pujantes oligarquías urbanas ${ }^{80}$. En este desarrollo, los acuerdos tanto como los enfrentamientos entre los integrantes de los linajes, así como entre éstos y la Corona y el común de los vecinos, actúan como elementos dinamizadores de esta modalidad de propiedad.

\subsection{Estrategias parentales}

El mayorazgo tanto para las distintas casas nobiliarias como para las elites concejiles en proceso de rápida promoción se presenta como una modalidad de disposición de la riqueza que garantiza a sus beneficiarios no sólo la protección contra la amenaza del desmembramiento por vía de la herencia, sino también

77 El esquema es actualizado por Bartlett para explicar la fase de conquista territorial, BARTLETT, R.: La formación de Europa. Conquista, colonización y cambio cultural, 950-1350, Valencia, PUV, 2003.

78 GARCÍA DÍAZ, I.: op. cit., p. 146.

79 Este es el caso de la elite jerezana estudiado por RUIZ PILARES, E.: op. cit.

80 El papel de los mayorazgos en la consolidación de los núcleos de poder oligárquico en un contexto creciente de «democratización» de la propiedad vinculada, extendida incluso como práctica de los sectores «plebeyos» es destacado por MONTILLA GARCÍA, M. A.: op. cit., pp. 194 y 197. 
contra el acecho del activo capital usurario que merma los recursos de propietarios de distinta cuantía y condición ${ }^{81}$. No obstante, las rivalidades internas por la disposición del patrimonio familiar, obligan al titular del privilegio a actuar con cautela para garantizar la reproducción de los parientes excluidos ${ }^{82}$.

Las enajenaciones, los traspasos y permutas de bienes con el objetivo de asegurar la solidez patrimonial del linaje forman parte de esta lógica tendiente a preservar la unidad y la cohesión del grupo ${ }^{83}$. Así es como si bien se protegen los intereses de las familias, también se incentivan sus contradicciones internas ${ }^{84}$. Las lógicas de solidaridad parental y la búsqueda de rentabilidad económica de los titulares son las principales causas que subyacen a los recurrentes «argumentos de justificación para alterar lo inalterable» ${ }^{85}$.

La propiedad vinculada tiende a afianzar la conservación de determinados bienes para evitar la dispersión intergeneracional; pero con ello, la instauración del principio de inalienabilidad contradice otras estrategias de reproducción fundamentales ${ }^{86}$. La inmovilidad de recursos incluidos en un mayorazgo no sólo excluye a otros parientes sino que dificulta la realización de matrimonios favorables, la entrega de dotes como medio de reforzamiento de alianzas políticamente claves, y hasta impide un reordenamiento de las propiedades en torno del lugar de implantación de los linajes ${ }^{87}$.

Estas cuestiones explican la violación práctica del principio de inalienabilidad $^{88}$, dado que las enajenaciones constantes «funcionaban como elementos correctores de los abusos y también de las contradicciones internas del sistema» ${ }^{89}$. Así se advierte cómo una de las más frecuentes causas de la alienación de parte de la propiedad vinculada es la necesidad de contar con recursos con los cuales dotar a las hijas para sellar uniones beneficiosas; dote y mayorazgo constituyen dos estrategias de reproducción que no siempre pueden permanecer

81 MARCOS MARTÍN, A.: op. cit., pp. 121-122.

82 QUINTANILLA RASO, M. C.: op. cit., pp. 500-501.

83 «la existencia de procesos de enajenación complejos, motivados por una interesante, e igualmente compleja, estrategia de linaje, a un tiempo matrimonial y patrimonial», Idem, p. 502.

${ }_{84} \mathrm{De}$ la «colisión entre dote y mayorazgo» sale triunfante la primera, MARZAL RODRÍGUEZ, P.: «Una visión jurídica de los mayorazgos valencianos entre la época foral y la Nueva Planta», Anuario de Historia del Derecho Español, LXVI (1996), pp. 229-230, esp. 257 y CATALÁ SANZ, J. A.: op. cit., pp. 61-95.

${ }^{5}$ QUINTANILLA RASO, M. C.: «Identidad y patrimonio. Salvaguarda y transmisión en las casas nobiliarias castellanas a finales del Medioevo. La casa condal de la puebla del maestre», En la España Medieval, n.․ Extra 1, (2006), pp. 157-182, esp. 160.

${ }^{86}$ Los testadores aparecen «atrapados en el dilema de preservar el patrimonio, el prestigio y la memoria de la casa sin dañar los derechos sucesorios del resto de los hijos, de quienes, a fin de cuentas, dependía la perpetuación de la familia, su dignidad, títulos y bienes si se truncaba la línea de primogenitura», CATALÁ SANZ, J. A.: op. cit., p. 71.

87 La generalización de los topolinajes y su relación con los cambios en el sistema de propiedad en ORTEGA CERVIGÓN, J. I.: op. cit., p. 154.

88 «las propiedades del mayorazgo eran inalienables, pero en la práctica, y como sucedió en multitud de mayorazgos, los reyes solían dar licencia para disponer de esos bienes», CARMONA RUIZ, M. A.: op.cit., p. 119.

89 QUINTANILLA RASO, M. C: «Propiedad vinculada», op. cit., p. 500. 
en armonía ${ }^{90}$. La difusión de esta práctica lleva a la propia monarquía a ratificar la expresa prohibición de enajenar cosa alguna del mayoradgo, en una Provisión de Isabel I de finales del siglo $\mathrm{XV}^{91}$.

Del mismo modo, la obtención de dignidades eclesiásticas y el acceso al crédito son otros de los motivos que estimulan la segregación de parte de los bienes que gozan de este privilegio ${ }^{92}$. Nos hallamos en el plano de las diversas estrategias de ampliación del poder y la fortuna de los grupos dominantes ${ }^{93}$, desde el cual se revela un tipo de propiedad no estático, inmerso en una activa gestión de los patrimonios orientada a la consecución de objetivos económicos y sociopolíticos más vastos ${ }^{94}$.

La implantación de núcleos señoriales se entrelaza con la fundación de propiedades incluidas en este régimen particular, dentro de la conformación de posiciones de preeminencia local desde las que proyectarse ${ }^{95}$. La disposición de potestades jurisdiccionales, el acceso a las rentas reales, las alianzas matrimoniales estratégicas y una política patrimonial agresiva, confluyen en el fortalecimiento de las principales familias del reino ${ }^{96}$.

En este contexto, puede advertirse que el inherente dinamismo histórico del mayorazgo es producto de la misma configuración del poder de los sectores privilegiados. Ampliación de los recursos, reacomodamiento de los patrimonios, traspasos, cesiones, compraventas, trueques y apropiaciones de distinto tipo, son las prácticas recurrentes de quienes alcanzan este privilegio ${ }^{97}$. La ofensiva de las

90 El arraigo de la práctica de reparto equitativo del patrimonio y el malestar de las parentelas ante su perturbación alcanza la literatura: «Contemplo, de sangre, igual/ dos cosas tan desiguales.../Más, ¿Cómo en dote lo son?/ Que, hermanas, fuera razón/que los tuvieran iguales», LOPE DE VEGA, F.: La dama Boba, Madrid, Espasa-Calpe, 1946, Acto I, 155. Sobre el derecho común en la literatura, MARTÍNEZ MARTÍNEZ, F.: «Derecho común y literatura: dos ejemplos de los siglos XVI y XVII», Anuario Mexicano de Historia del Derecho, 17, (2005), pp. 113-210.

91 Alí se prohíbe al duque de Nájera que «non vendades nin troquedes nin donedes nin dedes por titulo de dote nin arras", Archivo General de Simancas Registro General del Sello, Diversos de Castilla,

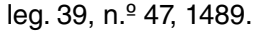

92 Las numerosas solicitudes al rey para enajenar el patrimonio vinculado señalan las contradicciones del sistema, véase USUNÁRIZ GARAYOA, J. M: op. cit.

93 Un estudio descriptivo de las estrategias de los linajes más prominentes en MUÑOZ GÓMEZ, V., «Transmisión patrimonial y estrategias de linaje. La herencia de Fernando de Antequera (1415-1420)», en DEL VAL VALDIVIESO, M. I.; MARTÍNEZ SOPENA, P.: op. cit., pp. 423-440.

94 QUINTANILLA RASO, M. C.: «Propiedad vinculada», op. cit., p. 509.

95 Así se aprecia en los señoríos abulenses de Villatoro, Cardiel y Navamorcuende, estudiados por MORENO NÚÑEZ, J. I.: Ávila y su tierra, op. cit.; Idem, op. cit., 2007. Los mayorazgos constituyen un conjunto patrimonial amplio que se va incrementando con la incorporación a su núcleo original de señoríos, inmuebles urbanos y rurales, además de rentas como servicios y montazgos,

96 Al respecto, GARCÍA DÍAZ, I.: op. cit., p. 148, 149; DE CEBALLOS-ESCALERA GILA, A.: «Un antiguo mayorazgo palentino. El de los señores de Santa Cruz, Castillejo y las Torres de Reinoso", Publicación de I Institución Tello Téllez de Meneses, 78, Palencia (2007), pp. 115-140.

97 Si bien restringido al estudio de la alta nobleza, Quintanilla Raso destaca la importancia de los cambios del mayorazgo dentro de la política económica de este sector; orientada al lucro y a maximizar la rentabilidad bajo nuevos criterios de racionalidad, QUINTANILLA RASO, M. C.: «Propiedad vinculada», p. 497. 
principales familias para acrecentar sus propiedades incluye conductas abiertamente lesivas de la legalidad, así como otras que encuentran en la merced regia su ratificación.

La incorporación al mayorazgo de los bienes cuya adquisición es producto de esta diversidad de estrategias, forma parte de la lógica de reproducción de los omnes poderosos; entendida ésta no en términos estrechamente económicos, sino dentro de una trama de construcción amplia de poder. Saber aprovechar las circunstancias favorables suele ser una de las claves del ascenso de muchas familias menores, pertenecientes a ramas secundarias que, desde un modesto patrimonio y una discreta influencia social, se elevan a situaciones de primacía ${ }^{98}$.

En el acto de creación de mayorazgos se entrelazan bienes económicos y dignidades simbólicas cuyo efecto social y político se asocian a un apellido ${ }^{99}$. El mayorazgo se inscribe en la conciencia de los antepasados, de modo que con la trasmisión de la herencia material, también se comunica la memoria del linaje que sostiene su cohesión y permanencia en la historia ${ }^{100}$.

\section{REFLEXIONES FINALES}

Ha sido interés de esta colaboración captar la realidad del mayorazgo dentro del desarrollo político, económico y social de la baja Edad Media. En este sentido, considerar no sólo su génesis y conformación, sino sus variables manifestaciones, posibilita advertir que aún las propiedades más sólidas están sometidas a contradicciones ${ }^{101}$. Esta ambivalencia del fenómeno, no se resuelve desde una mirada limitada al plano doctrinario, sino observando en cada caso la relación de fuerzas entre los protagonistas.

Las quiebras en el orden sucesorio, la existencia de mayorazgos de agnación rigurosa o artificiosa, las disputas que comprometen a diferentes miembros de la clase de poder, dan cuenta del proceso dinámico que lleva a la constitución de un tipo de propiedad idealmente tipificado como absoluto pero constantemente sometido a manipulaciones y presiones ${ }^{102}$.

Las restricciones contempladas en el régimen sucesorio que impone a los herederos la imposibilidad de enajenar los bienes recibidos, son otras de las limi-

${ }_{98}$ Esta trayectoria en la que confluyen distintas fuentes de poder en PALENCIA HERREJÓN, J. R.: op. cit., p. 338.

99 HEUSCH, C.: «La pluma al servicio del linaje. El desarrollo de los nobiliarios en la Castilla Trastámara", e-Spania, 11 (2011). http://e-spania.revues.org/20313 (consultado: 22-11-2012).

100 RUIZ PILARES, E.: op. cit.

101 «el sólido edificio de la propiedad vinculada se encontraba inmerso en un mundo de contradicciones, que provocaba inevitables fracturas», QUINTANILLA RASO, M. C.: «Propiedad vinculada», pp. 499-500.

${ }_{102}$ El concepto de «manipulación del mayorazgo», Ídem: p. 496. 
taciones. De allí que si bien expresa una modalidad de propiedad particular protegida - por fuera de los lazos personales que configuran la propiedad condicional-, los beneficiarios del mayorazgo lejos están aún de convertirse en propietarios «libres y plenos» ${ }^{103}$. «En su forma pura pues, la noción de propiedad absoluta era por completo extraña al régimen del feudalismo» 104 .

La inscripción del mayorazgo dentro de la evolución de la propiedad en el feudalismo, permite comprender sus lazos con los procesos políticos que atraviesan la Edad Media. En este sentido, la prioridad que tiene la configuración política de las formas de propiedad sitúa el fenómeno dentro del entramado estratégico de los diferentes grupos sociales.

La caracterización del mayorazgo desde la perspectiva de la historia social del poder que sostenemos en este trabajo, posibilita reconocer por sobre la diversidad de sus expresiones concretas, sus atributos sustantivos. Se trata de una modalidad patrimonial y de poder de los sectores privilegiados que tiende a proteger, asegurar y afianzar los recursos de las familias. No obstante, ese carácter protegido, como hemos planteado en el desarrollo precedente, no garantiza su permanencia inalterada. Por el contrario, es en la posibilidad de recurrir a la vinculación de parte de los bienes, tanto para apartarlos de la dinámica de fragmentación, como para apelar a ellos para responder a las necesidades del conjunto del linaje, donde radica la fortaleza de esta institución, considerada como herramienta estratégica.

El mayorazgo importa una institución de poder. Su fundación implica el punto de llegada de una acumulación previa, así como el inicio de activas políticas parentales orientadas a la construcción de nuevas posiciones de preeminencia social y económica. De este modo, pensamos el mayorazgo como parte de la lógica de reproducción de la clase estamental. Sus contradicciones revelan las tensiones que recorren el complejo proceso de configuración de los sectores privilegiados.

103 «los mayorazgos no alcanzaron toda su entidad hasta que los bienes vinculados formaron un bloque no divisible, de manera que el titular del mismo, una vez constituido, no estaba autorizado a disponer de ellos libremente», RUIZ PILARES, E.: op. cit., p. 338.

104 ASTARITA, C.: «Caracterización económica de los caballeros villanos de la Extremadura castellano leonesa, siglos XII-XV», Anales de Historia Antigua y Medieval, vol. 27 (1994), pp. 11-84, esp. 21 (destacado nuestro). 